Marion J. Ball, President of IMIA

Baltimore, USA

\title{
Preface
}

\section{A New IMIA Tradition}

It is indeed an honor to provide the Preface to the second edition of the Yearbook of Medical Informatics and no small challenge to follow upon Jos Willems in doing so as President of IMIA.

Last year, the first IMIA Yearbook of Medical Informatics was published thanks to the hard work and commitment of Jan H. van Bemmel and Alexa T. McCray, and the managing editors from the Editorial Office. Brought into print by Schattauer Publishing Company, the 1992 Yearbook was prominently displayed at MEDINFO 92 in Geneva, and 10,000 copies were distributed worldwide.

The 1993 Yearbook continues and enriches this new IMIA tradition. Once again, the editors have selected for reprint 46 articles from 28 journals specializing in or touching upon medical informatics. The selections span the globe from Indian Pediatrics to Acta Psychiatrica Scandinavica, encompass specialties from Diabetes Care to Anesthesiology, and bring together professions with such publications as from the Bulletin of the Medical Library Association to the Journal of the American Medical Association and IBM Systems Journal.

As they did last year, the editors of the 1993 Yearbook analyzed and categorized the articles selected for inclusion, after review by a large international editorial committee. As one committed to medical informatics, I direct you to their Editorial for insights into advances in this interdisciplinary science.

New in 1993, the Yearbook offers three Review Papers written especially for publication within these pages. These are UMLS, Unified Medical Language System (Donald A. B. Lindberg, USA), Standardization in Medical Informatics (George De Moor, Belgium), and Security in Medical Information Systems (Ab Bakker, The Netherlands). By providing reviews of work in these critical areas, the Yearbook speaks to health professionals and vendors working to implement medical informatics findings and thereby transform health care.

With this second iteration, the Yearbook builds upon the promise of the first volume and becomes a more established product for IMIA.

By offering facts, figures, and background information in addition to the scientific and review articles, the Yearbook supports IMIA's outreach to scientific, practitioner, and vendor communities around the globe.

\section{From Theory into Practice}

This outreach is critical to IMIA.

An Association of Associations, IMIA has committed to pursue a new role as bridge organization to other sectors beside the informatics associations representing its member 
countries. Increasingly, the IMIA Board and the constituencies that IMIA serves realize that informatics must move from theory into practice.

The technologies may not be perfect, and probably never will be, but they are sufficiently mature and robust to support real changes in health care, far beyond the academic setting.

The challenge that IMIA has taken is to reach out, to bridge the distances between professionals operating in different spheres, while striving to meet the same challenges. As past IMIA president Hans Peterson has stated on many occasions, it is time to implement the concepts and applications which the IMIA membership has played a critical role in developing.

To facilitate the move from theory into practice, IMIA has this past year established a new membership category, welcoming institutional members into the organization. These new members include vendors, consultants, and universities. IMIA is also strengthening its relationships with other professional organizations, such as the International Federation for Information Processing (IFIP), the World Health Organisation (WHO), the International Society of Technology Assessment in Health Care (ISTAHC), and the International Federation for Medical and Biological Engineering (IFMBE), among others. By building bridges between these and other spheres, IMIA hopes to foster collaborative initiatives and thus to support informatics as an essentially interdisciplinary science.

Forums will give institutional members the opportunity to dialogue with the informaticians within IMIA and its member societies. These exchanges and the resulting understandings can strengthen the link from practice to theory, enabling vendors and practitioners to benefit from IMIA's expertise. Only then will informatics move from theory into practice. Only then will the concepts and applications developed by the forward thinking academicians in health informatics move out into the community at large.

With these new alliances, IMIA gains visibility and vitality.

IMIA is co-sponsoring meetings offered by other professional associations and academic institutions, and offering an ambitious calendar of IMIA-sponsored events as well.

The IMIA calendar of events for 1993 includes a number of working conferences, including conferences on organizational development and physician workstations. This year, the first IMIA-sponsored conference in Africa was held, with the support of colleagues in Finland and the World Health Organisation, among others. True to the IMIA tradition, working conferences continue to draw attendees from around the world and across the professions. Academicians and clinicians are being joined by institutional members, who are expressing strong interest in attending and contributing to those events and building relationships within the larger informatics community. Proposals for new working groups in Technology Assessment, Pharmaco-Informatics, and Health Evaluation suggest IMIA's expanding scope and growing constituencies. Reviewed by theBoard in Jerusalem, these proposals will go to the General Assembly for approval at the Fall 1993 meeting in Japan.

\section{Healthcare Informatics}

Through its reprints, the Yearbook of Medical Informatics gives wider distribution to informatics research findings. Through its review articles, it reports on the state of the art in informatics. Through its information on the activities of IMIA and its Member Societies, it surveys the informatics scene.

The Yearbook furthers the evolving field of medical informatics. As a publication, it provides visibility to a vital and volatile discipline. The work the Yearbook represents both rises from and gives rise to IMIA activities. More important to us all, this work and the work it inspires will shape health care practices and delivery into the next century.

To this Yearbook, its editors, referees, synopsis writers, reviewers, and its contributors, including those behind the scenes and not named on these pages, we all owe a debt of thanks. 